\title{
Lusioersily
}

\section{Photo-Electrochemical Properties of Anodised Titania Nanotube Arrays Annealed in Nitrogen Atmosphere}

Wadhwa, S., Mathur, A., Hamilton, JWJ., Dunlop, PSM., \& Byrne, JA. (2015). Photo-Electrochemical Properties of Anodised Titania Nanotube Arrays Annealed in Nitrogen Atmosphere. Advanced Science Engineering and Medicine, 7(9), 761-770. https://doi.org/10.1166/asem.2015.1757

Link to publication record in Ulster University Research Portal

\section{Published in:}

Advanced Science Engineering and Medicine

Publication Status:

Published (in print/issue): 01/09/2015

DOI:

10.1166/asem.2015.1757

\section{Document Version}

Author Accepted version

\section{General rights}

Copyright for the publications made accessible via Ulster University's Research Portal is retained by the author(s) and / or other copyright owners and it is a condition of accessing these publications that users recognise and abide by the legal requirements associated with these rights.

\section{Take down policy}

The Research Portal is Ulster University's institutional repository that provides access to Ulster's research outputs. Every effort has been made to ensure that content in the Research Portal does not infringe any person's rights, or applicable UK laws. If you discover content in the Research Portal that you believe breaches copyright or violates any law, please contact pure-support@ulster.ac.uk. 


\title{
Photo-electrochemical properties of anodised titania nanotube arrays annealed in nitrogen atmosphere
}

\author{
S Wadhwa ${ }^{* a}$, A Mathur ${ }^{a}$, JWJ Hamilton ${ }^{b}$, PSM Dunlop ${ }^{b}$, JA Byrne ${ }^{b}$ \\ *a Amity Institute of Nanotechnology, Amity University, Sec 125, Noida, Uttar Pradesh, India \\ ${ }^{b}$ Nanotechnology and Integrated Bio-Engineering Centre, University of Ulster, Jordanstown, Shore \\ Road, Newtownabbey BT37 0QB, Northern Ireland (UK)
}

Date of submission: 18 June 2015

Date of acceptance: 18 June 2015

Corresponding author: S Wadhwa

Email: swadhwa@amity.edu

Tel: +919711202698 


\begin{abstract}
Self organised aligned titania nanotubes were synthesised by electrochemical anodisation of titanium foil and the effect of annealing in nitrogen atmosphere was investigated. The diameter and length of nanotubes were 90-110 $\mathrm{nm}$ and 450-500 $\mathrm{nm}$ respectively giving high aspect ratio nanomaterial. Samples annealed in nitrogen atmosphere were found to retain the tubular structure with diameter $80-110 \mathrm{~nm}$. Annealing of nanotubes in nitrogen atmosphere indicated substitution of nitrogen into the $\mathrm{TiO}_{2}$ lattice; however large amounts were still present as physisorbed, chemisorbed and possibly as $\mathrm{O}-\mathrm{Ti}-\mathrm{N}$ structure in $\mathrm{TiO}_{2}$ lattice. The photo-electrochemical properties of titania electrodes were investigated under solar simulated and visible illumination. The effect of methanol as hole acceptor was also investigated. The electrodes annealed in $\mathrm{N}_{2}$ atmosphere demonstrated higher solar photocurrent response than air annealed electrode. The sample annealed for $1 \mathrm{~h}$ in $\mathrm{N}_{2}$ resulted in optimum photocurrent response under solar simulated illumination. The photocurrent response obtained with the electrolyte containing methanol was found to be increased by a factor of 2.4 under solar simulated light and 1.3 under visible illumination, however the overall visible photocurrent response was very small compared to the solar simulated response. The additional small peaks at negative potentials may involve excitation from filled defect level.
\end{abstract}

Keywords: electrochemical, anodisation, photo-electrochemical, hole acceptor, photocurrent, defect

\title{
Corresponding author: S Wadhwa
}

Email: swadhwa@amity.edu

Tel: +919711202698 


\section{Introduction}

The most important factor determining efficiency in solar photocatalytic applications of existing materials' are their optical properties. As most stable photocatalysts are wide band gap materials e.g. $\mathrm{TiO}_{2}$ (3.2 eV for anatase; $3.0 \mathrm{eV}$ for rutile phase), thus efficient use of these materials is confined to a small proportion of the solar spectrum, limiting the total efficiency under solar irradiation. To improve efficiency over the entire solar spectrum it is essential to narrow down the band gap, to access longer wavelengths and hence improve its solar performance. This can be achieved by shifting the absorption edge to the visible region ${ }^{1}$. Various efforts have been made and are under further progress to achieve excitation in visible range. These include (i) doping with non-metals ${ }^{2}$ (ii) doping with metal ions ${ }^{3}$ (iii) sensitising $\mathrm{TiO}_{2}$ nanoparticles with other inorganic/organic compounds ${ }^{4}$ (iv) coupling $\mathrm{TiO}_{2}$ with narrow band gap semiconductors ${ }^{5}(\mathrm{v})$ preparing oxygen deficient $\mathrm{TiO}_{2}{ }^{6}$. Among other methods, high temperature annealing $\left(\sim 450-500^{\circ} \mathrm{C}\right)$ of anodised nanotube films, in the presence of nitrogen precursors such as ammonia $^{7,8}$ and hydrazine ${ }^{9}$, is commonly used to incorporate nitrogen. There is no direct report demonstrating nitrogen doping when nitrogen gas is used as a dopant precursor. However, electrical conductivities were enhanced upon annealing titania nanotubes in nitrogen in contrast to air or argon ${ }^{10}$. Annealing in gaseous $\mathrm{N}_{2}$ environment generates oxygen vacancies relatively easily under Ti-rich environment. ${ }^{11}$

In this work, the physical and photo-electrochemical properties of anodised titania nanotube films annealed in gaseous nitrogen atmosphere have been studied. Furthermore, the effect of addition of a hole acceptor on the photo-electrochemical properties of nanotubes was also studied.

\section{Experimental}

\subsection{Synthesis of aligned nanotubes by electrochemical method}

Ti foil (Sigma - Aldrich) was cut into $1.5 \times 1.5 \mathrm{~cm}^{2}$ square pieces and cleaned in an ultra-sonic bath in methanol for $15 \mathrm{~min}$. The cleaned Ti foil was anodised in custom designed two electrode electrochemical 
cell $(100 \mathrm{~mL})$. An area of $1 \mathrm{~cm}^{2}$ on Ti foil was exposed for anodisation. The electrolyte used was $1 \mathrm{M}$ $\mathrm{Na}_{2} \mathrm{SO}_{4}+0.12 \mathrm{M} \mathrm{NaF}$ aqueous solution. The Ti foil was treated at constant potential of $+25 \mathrm{~V}$ for $4 \mathrm{~h}$ using a stabilised power supply (Farnell) ${ }^{12}$. After anodisation, the foil was sonicated in methanol for 5 min to remove remnant salts.

\subsection{Annealing of nanotubes in nitrogen atmosphere}

Anodised titania nanotube samples were pre-treated in nitrogen atmosphere for $1 \mathrm{~h}$ at the flow rate of 50 $\mathrm{mL} / \mathrm{s}$ in a tube furnace prior to annealing. The pre-treated nanotube samples were annealed at $450^{\circ} \mathrm{C}$ (ramp up rate $\sim 20^{\circ} \mathrm{C} / \mathrm{min}$ ) in nitrogen at flow rate of $50 \mathrm{~mL} / \mathrm{s}$ for varying treatment times. After annealing, the furnace was allowed to cool down at room temperature with $\mathrm{N}_{2}$ flow rate of $10 \mathrm{~mL} / \mathrm{s}$. For comparison, one of the nanotube samples was annealed in air for $3 \mathrm{~h}$ at the same temperature.

\subsection{Electrode preparation}

All the samples were made into electrodes by attaching a $\mathrm{Cu}$ wire at the back using a conducting epoxy followed by curing of the contact at $120^{\circ} \mathrm{C}$ for about $30 \mathrm{~min}$. The contact, wire and the remaining area on Ti foil were masked using negative photoresist (KPR, Cassio chemicals) and cured under UV-B lamp (Philips) for $5 \mathrm{~min}$. The samples were baked again at $120^{\circ} \mathrm{C}$ for $15 \mathrm{~min}$ and the contact was sealed using epoxy resin (Araldite).

Surface characterisation was carried out using SEM (HITACHI S3200N). Crystalline phase was determined by XRD (Bruker-D8 Discover, $\mathrm{CuK} \alpha$ radiation) while phase composition was determined using XPS analysis (KRATOS AXIS Ultra, Al Ka source). The XPS spectra were referenced against C1s peak at $285 \mathrm{eV}$ and the analysis was carried out after subtracting Shirley background. 


\subsection{Electrochemical measurements}

Electrochemical measurements were carried out in a single compartment using three electrode electrochemical cell with a saturated Calomel reference and platinum paddle counter electrode. An Electrochemical workstation with PC control (Autolab PGStat30) provided potentiostatic control. The electrolyte was aqueous $0.1 \mathrm{M}$ sodium perchlorate $(\mathrm{pH} 5.6)$, with and without the addition of $6.0 \mathrm{M}$ methanol $(\mathrm{pH} \mathrm{5.9})^{13}$. A circular quartz window in the photo-electrochemical cell facilitated illumination of the working electrode. The irradiation source was a $1 \mathrm{~kW}$ xenon lamp (Speirs Robertson) with an AM1 filter for solar simulation. For visible light irradiation only, a UV cut-off filter was used (> $410 \mathrm{~nm}$ bandpass, Knight Optical). The incident light intensity was measured using a calibrated spectral radiometer (Jobin Yvon Gemini).

\section{Results}

\subsection{Characterisation of samples}

The ordered structure of nanotubes remained intact upon annealing in air or nitrogen at $450^{\circ} \mathrm{C}$ for different time periods (Figure 1). The diameter of nanotubes was measured to be $80-110 \mathrm{~nm}$, similar to the as-prepared anodised nanotube sample and the wall thickness was measured to be $20-25 \mathrm{~nm}$. This is consistent with the other studies ${ }^{7}$.

The diffraction patterns of as-synthesised nanotubes and those annealed in air and nitrogen atmosphere are shown in Figure 2. The as-synthesised nanotube sample exhibits strong diffraction peaks of metallic titanium with a very weak signal arising at $24.4^{0}$ corresponding to minuscule amounts of anatase. The asprepared sample is considered mainly amorphous requiring annealing to induce crystallinity. Strong peaks for metallic titanium are seen in all samples, presumably due to the open nature of the nanostructures exposing titanium substrates at the bottom of the nanotube. The air annealed sample showed a relatively strong diffraction peak for anatase around $24.7^{0}$. A few faint signals for rutile at $26.9^{0}$ and $35.5^{\circ}$ started to appear upon annealing the sample in air for $3 \mathrm{~h}$. All nanotube samples annealed in 
nitrogen atmosphere showed prominent diffraction peaks for anatase at $25.2^{0}$ and $47.4^{0}$, with some rutile peaks present. The XRD patterns of all annealed samples showed successful crystallisation consistent for titanium dioxide. Samples annealed in nitrogen atmosphere possess both the anatase crystallite structure of air annealed sample and small additional rutile signal at $53.5^{\circ}$. This agrees well with the other studies where nitrogen introduced into the titania lattice is too small to modify its crystallite structure considerably. $^{7,14}$

The average nitrogen content in $1 \mathrm{~h}, 3 \mathrm{~h}$, and $5 \mathrm{~h} \mathrm{~N}_{2}$ annealed samples were determined to be $2.15 \pm 0.18$, $2.12 \pm 0.23$, and $1.95 \pm 0.14$ at\% respectively. Analysis of the N1s region from the XPS spectrum of $1 \mathrm{~h}$ annealed sample (as it contains maximum at $\%$ of nitrogen) revealed binding energy peaks ranging from $390-406 \mathrm{eV}$. A smaller amount of nitrogen is also incorporated in air annealed sample (Figure 3). Peaks between 398 and $402 \mathrm{eV}$ in air and nitrogen annealed samples are indicative of chemisorbed nitrogen ${ }^{15}$. A peak in the range of $398.5-398.9 \mathrm{eV}$ in $\mathrm{N} 1 \mathrm{~s}$ binding energy region may be due to $\mathrm{O}-\mathrm{Ti}-\mathrm{N}$ structure ${ }^{18}$. Additional peaks in nitrogen annealed samples appear at $393 \mathrm{eV}$ and $406 \mathrm{eV}$. A broad peak at $393 \mathrm{eV}$ indicates that heat treatment lead to substitution of some amount of adsorbed nitrogen. However, a peak at $393 \mathrm{eV}$ is relatively small and broader than other prominent peaks around $400 \mathrm{eV}$ and above. This indicates that larger amount of nitrogen is in chemisorbed state. A peak at $406 \mathrm{eV}$ may be due to physisorbed $\mathrm{N}_{2}$.

Table 1 gives the N1s binding energies from the XPS data obtained. A summary of XPS binding energy data and the peak assignments for N1s region gathered from literature is given in Table 2. The peak around $402 \mathrm{eV}$ vanished in $5 \mathrm{~h}$ sample, indicating that the $\mathrm{N}_{2}$ was weakly bonded to the surface and is easily replaced by oxygen. Moreover, the absence of peaks at and beyond $407 \mathrm{eV}$ is in agreement with the absence of chemisorbed $\mathrm{NO}$ or $\mathrm{NO}_{2}$ species ${ }^{17}$.

\section{Table 1}




\section{Table 2}

As indicated previously, annealing in gaseous $\mathrm{N}_{2}$ environment generates oxygen vacancies relatively easily under Ti-rich environment. This is also indicated by the O1s region scan of one of the samples annealed in nitrogen (Figure 4). Two O1s peaks around $530 \mathrm{eV}$ and $532 \mathrm{eV}$ were observed in all samples, including air annealed sample. An additional peak at $532 \mathrm{eV}$ is attributed to $\mathrm{O}-\mathrm{Ti}-\mathrm{N}$ structure ${ }^{19}$ due to more covalent nature of $\mathrm{N}-\mathrm{TiO}_{2}$. This may be an indication of presence of oxygen and nitrogen in the same lattice units ${ }^{18}$. The $\mathrm{O} 1 \mathrm{~s}$ peak for $\mathrm{NO}$ and $\mathrm{NO}_{2}$ appears at $533.5 \mathrm{eV}$ in contrast to $532 \mathrm{eV}$, therefore the possibility of formation of $\mathrm{NO}$ or $\mathrm{NO}_{2}$ species is completely discarded. ${ }^{20}$

Combining the XPS analysis of N1s and O1s binding energy regions, the different forms of nitrogen species that exist are weakly adsorbed $\mathrm{N}_{2}$, chemisorbed $\mathrm{N}_{2}$ and lattice doping $(\mathrm{O}-\mathrm{Ti}-\mathrm{N}$ structure $)$ in titania nanotube samples annealed in nitrogen atmosphere.

\subsection{Electrochemical properties of titania nanotubes}

\subsubsection{Photocurrent response of titania nanotubes}

The photocurrent response of titania nanotubes annealed in nitrogen atmosphere for 1,3 and $5 \mathrm{~h}$ were compared with that of the sample annealed in air for $3 \mathrm{~h}$ (Figure 5). The electrolyte used was aqueous 0.1 $\mathrm{M} \mathrm{NaClO}_{4}$ aqueous.

All samples demonstrated negligible anodic current in the dark. The photocurrent, $I_{p h}$ and the photocurrent density, $J$ used in the text and the figures refers to complete sample irradiation as the surface areas of the electrodes were $1 \mathrm{~cm}^{2}$. The $\mathrm{I}_{\mathrm{ph}}$ of air annealed sample under solar simulated illumination was $0.16 \mathrm{~mA}$ at $+1.0 \mathrm{~V}$ and the onset potential was $-0.6 \mathrm{~V}$. The $\mathrm{I}_{\mathrm{ph}}$ produced by samples annealed in nitrogen were only slightly greater than air annealed sample under solar simulated light. The values of $\mathrm{I}_{\mathrm{ph}}$ obtained for samples annealed in nitrogen for 1,3 and $5 \mathrm{~h}$ were $0.19 \mathrm{~mA}, 0.17 \mathrm{~mA}$, and $0.18 \mathrm{~mA}$ at $+1.0 \mathrm{~V}$. The 
onset potentials were $-0.3 \mathrm{~V},-0.6 \mathrm{~V}$, and $-0.5 \mathrm{~V}$ respectively. The shoulders in the curves at negative potentials following the onset potential in each case (indicated by arrows in the Figure 5) may involve changes in trapping/donor characteristics unique to different defect level distributions in each sample. It is reported that filled defect levels may act as electron donor states under appropriate applied potential, resulting in higher photocurrents ${ }^{21}$. From Figure 5, it is clear that nanotube arrays produce an enhanced photocurrent response under solar simulated light. It has already been established that nanotube arrays annealed at temperature $450^{\circ} \mathrm{C}$ produces photocurrent about 10 times higher photocurrent than Degussa P25 under solar simulated light ${ }^{22}$. To further investigate the origin of enhanced photocurrent, the visible light photocurrent response of the samples was examined. The electrodes annealed in nitrogen atmosphere show negligible anodic photocurrent response under visible illumination. This is exemplified by the photocurrent response of $1 \mathrm{~h}$ sample under solar and visible illumination (Figure 6). However, a small photocurrent response around $-0.3 \mathrm{~V}$ may indicate electron excitation from filled defect level. Similar small peaks at negative potentials under sub-band gap irradiation were reported for metal doped $\mathrm{TiO}_{2}$ electrodes. $^{21}$

It is evident from Figure 5 and Figure 6 that the photocurrent response, demonstrated by nanotube electrodes was primarily due to the band gap excitation by UV light. It is reported that the photocurrent response is significantly influenced by physical features of the nanotubes such as nanotube length ${ }^{15}$ and wall thickness ${ }^{23}$. Macak et al. ${ }^{15}$ found significantly higher UV photocurrent response for $\mathrm{N}$-doped titania nanotube array with thickness around $500 \mathrm{~nm}$ when compared to the photocurrent response of longer nanotube arrays $(\sim 6 \mu \mathrm{m})$. They also found lowest photocurrents under visible light for shorter nanotubes in comparison to longer nanotube arrays. The difference in the visible spectral response of nanotube arrays was attributed to the recombination effect which is more pronounced in the "rough" surfaces of short arrays than relatively "smooth" surfaces of long arrays. They attributed the loss of UV photocurrent response in longer nanotubes to the recombination effects along the length of the tubes. It must be noted that substitutional doping (characterised by N1s binding energy peak at $396 \mathrm{eV}$ ) is not the only cause of 
visible light activity. Macak et al. confirmed substitutional $N$-doping ( $\beta$-N state) by the appearance of N1s peak at $396 \pm 0.2 \mathrm{eV}$ for long $(6 \mu \mathrm{m})$ and medium $(2.5 \mu \mathrm{m})$ length nanotube arrays but observed significant differences in the visible spectral responses of the two types of nanotube arrays ${ }^{15}$. This also indicates that introduction of N1s states within the band gap does not always lead to enhanced visible light activity. Sakthivel et al. observed band gap narrowing and efficient photoctalytic activity under diffuse indoor lights with the only peak at $404 \mathrm{eV}$ due to hyponitrite structure in N-doped sample ${ }^{24}$. Similarly, visible light activity was attributed to co-doping effect between nitrogen and hydrogen ${ }^{25}$, reduction of $\mathrm{Ti}^{4+}$ to $\mathrm{Ti}^{3+}$ sites and formation of oxygen vacancies (color centers) ${ }^{26}$, and impurity sensitisation. ${ }^{27}$

The enhancement of photocurrent in UV light and insignificant photocurrent response of our $\mathrm{N}_{2}$ annealed samples under visible light indicate that annealing nanotubes under nitrogen atmosphere has not effectively shifted the band gap enough to produce visible spectral response. This is likely due to small amounts of dopant introduced into the lattice. To essentially introduce band gap narrowing and its consequent effects on the electronic properties, the material needs to be heavily doped ${ }^{26}$. Moreover, $\mathrm{N}_{2}$ as gaseous source requires much larger nitrification energies (the dissociation energy is $9.9 \mathrm{eV}$ ) compared to other sources such as NO (the dissociation energy is $6.6 \mathrm{eV}) .^{11}$

\subsubsection{Effect of addition of methanol on photocurrent response}

The effect of the addition of methanol as a hole scavenger was investigated under solar simulated irradiation (Figure 7). No sample gave anodic current in the dark. The onset of anodic photocurrent was around $-0.94 \mathrm{~V}$ for all samples, including the air annealed electrode. The $\mathrm{I}_{\mathrm{ph}}$ values measured were 0.46 $\mathrm{mA}, 0.37 \mathrm{~mA}, 0.41 \mathrm{~mA}$ and $0.37 \mathrm{~mA}$ at $+1.0 \mathrm{~V}$ vs SCE for samples annealed in $\mathrm{N}_{2}$ for $1 \mathrm{~h}, 3 \mathrm{~h}, 5 \mathrm{~h}$ and in air respectively. The photocurrent responses for the electrodes annealed in $\mathrm{N}_{2}$ were, in general, slightly greater than that of the air annealed electrode under simulated solar illumination. However, the photocurrent response of $3 \mathrm{~h}$ sample and air annealed sample were similar. The $1 \mathrm{~h}$ sample demonstrated 
the highest photocurrent among all the samples. The photocurrent responses of the samples under solar illumination follow the order:

\section{$1 \mathrm{~h}>5 \mathrm{~h}>3 \mathrm{~h} \approx$ air annealed}

The effect of addition of $6.0 \mathrm{M}$ methanol to the electrolyte $0.1 \mathrm{M} \mathrm{NaClO}_{4}$ on the photocurrent response of annealed titania nanotube electrodes was studied under solar and visible illumination. Figure 8 shows the effect of the addition of methanol on the photocurrent response of $1 \mathrm{~h}$ sample under simulated solar illumination.

The $\mathrm{I}_{\mathrm{ph}}$ obtained for $1 \mathrm{~h}$ sample under solar simulated light with and without methanol were $0.46 \mathrm{~mA}$ and $0.19 \mathrm{~mA}$ respectively. The $\mathrm{I}_{\mathrm{ph}}$ value obtained with the electrolyte containing methanol is increased by a factor of 2.4 under solar simulated light. Figure 9 shows the visible photocurrent response of $1 \mathrm{~h}$ sample with and without the addition of methanol to the electrolyte. The $\mathrm{I}_{\mathrm{ph}}$ values obtained in $\mathrm{NaClO}_{4}$ electrolyte only and with the addition of methanol were 1.84 and $2.47 \mu \mathrm{A}$ respectively, exhibiting an increase by a factor of 1.3 with the addition of methanol. Though the $\mathrm{I}_{\mathrm{ph}}$ was increased, the overall visible photocurrent response with the addition of methanol was not significant.

Again, small anodic peaks were observed at negative potentials, for the nitrogen annealed sample $(1 \mathrm{~h})$ in Figure 8 (indicated by an arrow) and Figure 9. The decrease in current compared to the dark sample appears to be the removal of trapped holes by visible light and methanol scavenging. Nakamura et al. ${ }^{13}$ found an increase in the IPCE values of $\mathrm{N}$-doped $\mathrm{TiO}_{2}$ powders by a factor of 6-7 under UV illumination while the increase was only by a factor of 1.1-1.4 under visible illumination by the addition of $6.0 \mathrm{M}$ methanol to the $0.1 \mathrm{M} \mathrm{HClO}_{4}$. They found "current doubling" mechanism to be the main cause of enhanced photocurrent response under UV illumination with the addition of methanol ${ }^{28}$. This is the mechanism whereby one electron oxidation yields an unstable intermediate radical which is able to inject 
a second electron into the conduction band of the semiconductor. Thus, two electrons per photon are injected into the conduction band of a semiconductor causing a significant rise in the photocurrent.

\subsubsection{Current-time responses for titania nanotube electrodes}

The potential dependence of photocurrent in titania nanotube electrodes can be established from currenttime response measured at a fixed potential under chopped illumination (Figure 10).

The current-time behaviour of the samples is similar in topography to that of an $n$-type single crystal under chopped illumination, however, the timescales for current decay are in seconds, not milliseconds. ${ }^{29}$

The $\mathrm{I}_{\mathrm{ph}}$ st measured from Figure 10 were $0.14,0.18,0.16,0.17 \mathrm{~mA}$ for air and nitrogen annealed electrodes for $1 \mathrm{~h}, 3 \mathrm{~h}$, and $5 \mathrm{~h}$ respectively. Comparing the steady-state photocurrent values, the trend observed is quite similar to that observed on the basis of linear sweep voltammograms (Figure 5) under solar irradiation:

\section{$1 \mathrm{~h}>5 \mathrm{~h}>\mathbf{3} \mathrm{h}>$ air annealed.}

Xiao et al. observed higher photocurrent responses for titania nanotubes annealed in nitrogen in comparison with annealing in oxygen or argon and attributed it to the partial reduction of $\mathrm{Ti}^{4+}$ ions and formation of oxygen vacancies ${ }^{10}$. The reduction of $\mathrm{Ti}^{4+}$ sites leads to a higher photocurrent response and slower decay kinetics as indicated by Konenkamp ${ }^{30}$. The number and energetic position of defects within a structure can extend the lifetime of charge carriers by an order of magnitude.

The current-time responses for air and nitrogen annealed $(1 \mathrm{~h})$ electrodes under chopped solar simulated illumination in the applied potential range of $-0.8 \mathrm{~V}$ to $+1.0 \mathrm{~V}$ vs SCE are shown in Figure 11 and Figure 12. 
The potential dependence of the photocurrents observed during current-time responses of titania electrodes is discussed below. All nitrogen annealed electrodes gave similar photocurrent responses where the initial spike $\left(\mathrm{I}_{\mathrm{ph}}\right.$ in $)$ is evident in all electrodes. However, the cathodic photocurrent spike can only be seen clearly at $-0.4 \mathrm{~V}$ and $-0.2 \mathrm{~V}$ in both air and nitrogen annealed electrodes. For air annealed electrode, the steady state photocurrent is reached in about $15 \mathrm{~s}$ at fixed potentials of $0.0 \mathrm{~V}$ and $+0.2 \mathrm{~V}$, however the time taken to reach steady state starts decreasing with increasing applied potential above $+0.2 \mathrm{~V}$.

In $1 \mathrm{~h}$ sample, the steady state is reached in $20 \mathrm{~s}$ at $0.0 \mathrm{~V}$, decreasing thereafter down to $10 \mathrm{~s}$ at $+0.4 \mathrm{~V}$. The decrease in time to achieve steady state is further continued and takes only $2 \mathrm{~s}$ at $+0.6 \mathrm{~V}$ and $+0.8 \mathrm{~V}$.

To obtain more information on charge transport behaviour and critical band bending, denoted as “ $\Phi$ ”, flat

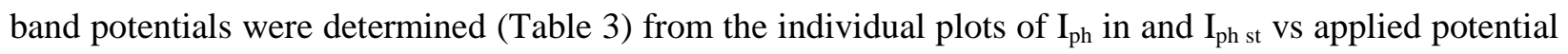
and the ratio $\mathrm{I}_{\mathrm{ph} \mathrm{st}} / \mathrm{I}_{\mathrm{ph}}$ is called "transient ratio" for all electrodes (plots not shown here). The flat band potentials were calculated using the following equation: ${ }^{31,32}$

$$
\Phi_{\mathrm{s}}=\left(E-E_{\mathrm{fb}}\right) \ldots \ldots \ldots \ldots \ldots \ldots \ldots \ldots \ldots . . \ldots \ldots \ldots \text { Equation } 1
$$

where $E$ is the potential at which transient ratio is close to unity and $E_{\mathrm{fb}}$ is the potential at which $\mathrm{I}_{\mathrm{ph}}$ in tends to zero.

\section{Table 3}

The flat band potentials for titania electrodes annealed in nitrogen were measured to be around $-0.50 \mathrm{~V}$. The $\Phi_{\mathrm{s}}$ were around $+1.30 \mathrm{~V}$, the values being fairly close to each other for all electrodes, however 
significantly less than that of air annealed sample (Table 3). This is in accordance with Figure 5 where the photocurrents observed were not significantly different from each other among electrodes annealed in nitrogen atmosphere. In a single crystal semiconductor, the transient ratio never attains the value of 1.0 as the possibility of recombination reaction cannot be disregarded completely. The steady-state photocurrent, $\mathrm{I}_{\mathrm{ph} \text { st }}$ tended towards zero around $-0.2 \mathrm{~V}$ in all samples, differing only slightly by $+0.02 \mathrm{~V}$ or $-0.02 \mathrm{~V}$ from one sample to another. The measured $\mathrm{I}_{\mathrm{ph} \text { st }}$ is about $0.3 \mathrm{~V}$ positive of flat band potential, $E_{\mathrm{fb}}$ in all cases. These results have some similarity with previously published report on the current-time responses of a single crystal titania in $1.0 \mathrm{M} \mathrm{Na}_{2} \mathrm{SO}_{4}$ electrolyte solution ${ }^{31}$. The $\mathrm{I}_{\mathrm{ph}}$ in extrapolating to zero near $E_{\mathrm{fb}}$ was reported. The transient ratio was found to increase exponentially, with an increase in critical band bending and reaching a plateau approaching unity for $\Phi_{\mathrm{s}} \geq 1$. The onset of the $\mathrm{I}_{\mathrm{ph} \text { st }}$ was found to be about $0.45 \mathrm{~V}$ positive of $E_{\mathrm{fb}}$. Furthermore, the kinetic model based on the effect of build up and decay of surface states on observed photocurrent transients was also developed ${ }^{31}$. The role of defect states and surface states has already been discussed previously.

\subsubsection{Effect of addition of methanol on current-time responses}

Methanol is a known hole acceptor and has shown to act as current doubling agent ${ }^{32}$ as discussed earlier. Figure 13 reveals the effect of electrolyte containing methanol at high concentration on solar photocurrent responses of titania electrodes. The $\mathrm{I}_{\mathrm{ph} \text { st }}$ from photocurrent responses of $1 \mathrm{~h}$ sample measured at $+1.0 \mathrm{~V}$ vs SCE with the supporting electrolyte was $0.18 \mathrm{~mA}$ whereas with the addition of methanol, it was observed to be $0.39 \mathrm{~mA}$, causing an increase in the value by a factor of about 2.2. A similar increase (by a factor of 2.0) in the photo-stationary current was observed for the air annealed electrode with the values $0.28 \mathrm{~mA}$ and $0.14 \mathrm{~mA}$ obtained with and without the presence of methanol in the supporting electrolyte. These results are in line with those of linear sweep voltammetry where a rise in solar photocurrent by a factor of 2.4 was demonstrated when the electrolyte containing methanol was used. 
Wahl et al. distinguished between the bulk microporous and nanostructured titania electrodes by studying the photocurrent-potential behaviour, taking the effect of electron and hole acceptors into consideration ${ }^{33}$. They reported that nanostructured particles do not support the formation of space charge layer as the particles are too small. Therefore, the anodic photocurrent depends on the actual rate of hole transfer to the reductant and inhibition of formation of intermediates or products that may act as recombination sites. Suppression of recombination reactions by the addition of hole acceptors is well reported ${ }^{34}$. The dissolved hole acceptor hampers the photoanodic formation of oxygen due to photooxidation of water. This in turn reduces the number of recombination sites for electron as oxygen acts as efficient electron scavanger. Furthermore, methanol undergoes rapid hole transfer reaction generating an unstable intermediate, $\mathrm{CH}_{3} \mathrm{O}$, following the reaction: ${ }^{33}$

$$
\mathrm{CH}_{3} \mathrm{OH}+\mathrm{h}^{+} \rightarrow \mathrm{CH}_{3} \mathrm{O} \cdot+\mathrm{H}^{+}
$$

The intermediate, $\mathrm{CH}_{3} \mathrm{O} \cdot$ undergoes further oxidation and injects second electron in the conduction band of titania as follows:

$$
\mathrm{CH}_{3} \mathrm{O} \cdot+\mathrm{h}^{+} \rightarrow \mathrm{HCHO}+\mathrm{H}^{+}+\mathrm{e}^{-}
$$

This leads to the injection of 2 electrons to the conduction band of titania per photon absorbed, complying with the rise in photocurrent on addition of methanol to the supporting electrolyte. Furthermore, there may be a localised effect of $\mathrm{pH}$ due to the oxidation of methanol in the electrolyte layer around the photoelectrode. This may shift the band edge potential more positive causing an increase in the photocurrent with time.

The potential dependence of photocurrent for the electrodes in the electrolyte containing methanol at high concentration under chopped solar illumination is evident at negative potentials (Figure 14 and Figure 
15). The current time responses demonstrate photoanodic spike appearing at negative potentials only. The photoanodic spikes do not appear at potentials $\geq 0.0 \mathrm{~V}$. The absence of photoanodic spike at positive potentials is not uncommon in the case of hole acceptors added to the electrolyte at such a high concentration.

The photocurrent decay following $\mathrm{t}_{0}$ was found to be less pronounced at relatively higher concentrations of oxalate added to the supporting electrolyte at positive potentials ${ }^{29}$. The photogenerated holes oxidise the hole acceptor very rapidly and the electrons diffuse out to the back contact producing a photoanodic spike. The photooxidation of water to liberate oxygen competes with the oxidation of added hole acceptor due to overall depletion of the hole acceptor in the electrolyte. The photogenerated electrons must encounter the region depleted of hole acceptors and/or containing photoanodically generated oxygen while diffusing out through the film to reach back contact electrode. Thus, this region serves as recombination channel for the photogenerated conduction band electrons, thereby leading to a decay of photocurrent. At higher concentrations, the photooxidised hole acceptors are replaced rapidly, hampering the photooxidation of water to liberate oxygen. Thus, the photocurrent decay following $\mathrm{t}_{0}$ is not prominent.

Also, the addition of methanol seems to have the effect of reversing the initial and steady state currents. Given konemkamps ${ }^{30}$ assessment that photocurrent trapping is the first step in all reactions a higher initial to steady state would infer that plenty of states are available to accept photogenerated charges with respect to the diffusion length of the charge carriers. Low initial to steady state would suggest that with respect to the diffusion length, acceptor states are saturated. However, the inversion (higher steady state compared to initial) in the presence of methanol could possibly be due to the removal of acceptor states due to the binding of methanol, wherein initially many of the acceptor states are saturated by methanol and only through continued oxidation of methanol do these sites become available for accepting charge carriers increasing the steady state for methanol binding reaction in $\operatorname{dark}^{35}$. 
The photogenerated conduction band electrons move to the back contact electrode via diffusion only in nanocrystalline microporous electrodes, and therefore, independent of applied potential. However, the efficiency of electron transport to the back contact electrode depends upon Fermi level of the contact electrode, which is a potential dependent process. A positive bias applied to the electrode leads to lowering of Fermi level of the contact electrode, thereby facilitating electron removal from the illuminated electrode ${ }^{29}$. This explains the potential dependence of photocurrents observed at negative potentials only when the electrolyte contains a hole acceptor. Figure 16 indicates that the transient ratios are slightly greater than 1.0 at $0.0 \mathrm{~V}$ giving a value in the range of 1.0 to 1.3 , and finally plateaus with increasing band bending. It has been illustrated before that the transient ratio plateaus giving a value close to 1.0 with increasing band bending, the value of which is dependent on the concentration of a hole acceptor $^{29}$. Figure 16 is in agreement with the current-time responses measured under chopped illumination and justifies the following observations made earlier: i) photoanodic spike present at negative potentials, indicating recombination of photoelectrons with oxidised species or hole traps present in the electrolyte layer around the photoelectrode, ii) the dependence of photocurrent on applied potentials in the range of $-0.8 \mathrm{~V}$ to $0.0 \mathrm{~V}$, iii) the transient ratio plateaus giving a value around 1.0 at positive potentials.

\section{Conclusion}

Self-organised titania nanotubes were synthesised by the electrochemical anodisation of titanium metal and annealed under air and nitrogen atmosphere with the aim of investigating the photo- electrochemical properties of the annealed nanotubes. The annealed samples were found to be predominantly anatase and the nanotube structure was found retained following annealing. Nitrogen was found to be present mainly as physisorbed, chemisorbed and possibly as $\mathrm{O}-\mathrm{Ti}-\mathrm{N}$ structure in the $\mathrm{TiO}_{2}$ lattice; however results indicate substitution of some amount of nitrogen into the lattice. This was also confirmed by analysis of 
the $\mathrm{O} 1 \mathrm{~s}$ peaks at 530 and $532 \mathrm{eV}$. The higher binding energy peak corresponded to $\mathrm{O}-\mathrm{Ti}-\mathrm{N}$ structure and indicated that oxygen vacancy states are easily formed upon annealing in nitrogen environment.

The electrodes annealed in nitrogen atmosphere demonstrated higher solar photocurrent response than air annealed electrode. The nanotube electrode annealed for $1 \mathrm{~h}$ in $\mathrm{N}_{2}$ was found to give optimum photocurrent response under solar simulated illumination. The photocurrent response obtained with the electrolyte containing methanol was found to be increased by a factor of 2.4 under solar simulated light. This may be attributed to the "current doubling" effect observed due to addition of a hole acceptor. The visible photocurrent response was increased by a factor of 1.3 in the presence of methanol, however the overall photocurrent response under visible illumination was very small compared to the solar simulated response. The additional small anodic peaks at negative potentials in linear sweep voltammograms may represent holes trapped at defect level. The current-time response of air and nitrogen annealed electrodes exhibited a photoanodic spike at all applied potentials in the presence of supporting electrolyte. The flat band potentials for the titania electrodes annealed under $\mathrm{N}_{2}$ were estimated to be $-0.50 \mathrm{~V}$ at $\mathrm{pH} 5.6$. The critical band bending $\left(\Phi_{\mathrm{s}}\right)$ was around $+1.30 \mathrm{~V}$ for all $\mathrm{N}_{2}$ annealed electrodes. The photocurrent decay following $t_{0}$ was found to be less prominent at positive potentials in the electrolyte containing a high concentration of methanol under chopped solar illumination. The transient ratios are in the range of 1.0 to 1.3 at positive potentials for all electrodes. The photo-oxidation of water and methanol using anodised titania electrodes annealed in a nitrogen atmosphere demonstrated that the UV photocurrent response can be increased to some extent, probably due to oxygen vacancies. The addition of methanol as a hole acceptor resulted in significant increase in the photocurrent response for both air annealed and nitrogen annealed samples.

Detailed photo-electrochemical measurements and analysis achieved in this work would lead to enhancement in the prior knowledge about nitrogen doping into titania nanotubes structure. This will 
provide an insight on the underlying mechanism of nitrogen incorporation into nanotubes structure and modifying its band gap properties.

\section{Acknowledgements}

The authors would like to acknowledge the funding received from the University of Ulster's Vice Chancellor's Research Scholarship (S. Wadhwa). We would like to extend our thanks to Dr G. Dale for helping with the setting up of the electrochemical anodisation method. 


\section{References}

1. R. Asahi, T. Morikawa, T. Ohwaki, K. Aoki and Y. Taga, Science, 293, 269 (2001).

2. H. Irie, Y. Watanabe and K. Hashimoto, J. Phys. Chem. B, 107, 5483 (2003).

3. J. W. J. Hamilton, J. A. Byrne, C. McCullagh and P. S. M. Dunlop, Int. J. Photoenergy, 1 (2008).

4. E. Bae and W. Choi, J. Phys. Chem. B, 110, 14792 (2006).

5. H. Tada, T. Mitsui, T. Kiyonaga, T. Akita and K. Tanaka, Nat. Mater., 782 (2006).

6. I. Nakamura, N. Negishi, S. Kutsuna, T. Ihara, S. Sugihara and K. Takeuchi, J. Mol. Catal. A-Chem., $161,205(2000)$.

7. L. Dong, Y. Ma, Y. Wang, Y. Tian, G. Ye, X. Jia and G. Cao, Mater. Lett., 63,1598 (2009).

8. R. P. Vitiello, J. M. Macak, A. Ghicov, H. Tsuchiya, L. F. P. Dick and P. Schmuki, Electrochem. Commun., 8, 544 (2006).

9. J. Xu, Y. Ao, M. Chen and D. Fu, Appl. Surf. Sci., 256, 4397 (2010).

10. P. Xiao, D. Liu, B. B. Garcia, S. Sepehri, Y. Zhang and G. Cao, Sens. Actuator B-Chem., 134, 367 (2008).

11. R. Asahi and T. Morikawa, Chem Phys., 339, 57 (2007).

12. G. R. Dale, J. W. J. Hamilton, P. S. M. Dunlop, P. Lemoine and J. A. Byrne, J. Nanosci. Nanotechnol., 9(7), 4215 (2009).

13. R. Nakamura, T. Tanaka and Y. Nakato, J. Phys. Chem. B, 108, 10617 (2004).

14. D. Lin, C. Guo-xi, M. Ying, J. Xiao-lin, Y. Guo-tian and G. Shao-kang, Trans. Nonferrous Met. Soc. China, 19, 1583 (2009).

15. J. M. Macak, A. Ghicov, R. Hahn, H. Tsuchiya and P. Schmuki, J. Mater. Res., 21(11), 2824 (2006).

16. V. Etacheri, M. K. Seery, S. J. Hinder and S. C. Pillai, Chem. Mater., 22, 3843 (2010).

17. J. A. Navio, C. Cerrillos and C. Real, Surf. Interface Anal., 24, 355 (1996).

18. M. Sathish, B. Viswanathan, R. P. Viswanath and C. S. Gopinath, Chem. Mater., 17, 6349 (2005).

19. X. Chen and C. Burda, J. Phys. Chem. B, 108,15446 (2004). 
20. J. A. Rodriguez, T. Jirsak, J. Dvorak, S. Sambasivan and D. Fischer, J. Phys. Chem. B, 104(2), 319 (2000).

21. J. W. J. Hamilton, J. A. Byrne, C. McCullagh and P. S. M. Dunlop, Int. J. Photoenergy, 1 (2008). doi:10.1155/2008/631597.

22. G. Dale, Electrochemical growth and characterisation of self-organised titania nanotubes. University of Ulster (2009).

23. G. K. Mor, O. K. Varghese, M. Paulose, K. Shankar and C. A. Grimes, Sol. Energy Mater. Sol. Cells, 90, 2011 (2006).

24. S. Sakthivel and H. Kisch, Chem. Phys. Chem., 4, 487 (2003).

25. O. Diwald, T. L. Thompson, T. Zubkov, E. G. Goralski, S. D. Walck and J. T. Yates, J. Phys. Chem. B, 108, 6004 (2004).

26. N. Serpone, J. Phys. Chem. B, 110, 24287 (2006).

27. S. Sato, R. Nakamura and S. Abe, Appl. Catal. A-Gen., 284, 131 (2005).

28. S. R. Morrison and T. Freund, J. Chem. Phys., 47, 1543 (1967).

29. J. A. Byrne and B. R. Eggins, J. Electroanal. Chem., 457, 61 (1998).

30. R. Könenkamp, R. Henninger and P. Hoyer, J. Phys. Chem., 97, 7328 (1993).

31. P. Salvador, J. Phys. Chem., 89(18), 3863 (1985).

32. J. A. Byrne, B. R. Eggins, S. Linquette-Mailley and P. S. M. Dunlop, Analyst, 123, 2007 (1998).

33. A. Wahl, M. Ulmann, A. Carroy, B. Jermann, M. Dolata, P. Kedzierzawski, C. Chatelain, A. Monnier and J. Augustynski, J. Electroanal. Chem., 396, 41 (1995).

34. S. K. Poznyak, A. I. Kokorin and A. I. Kulak, J. Electroanal. Chem., 442, 99 (1998).

35. N. A. M. Zabidi, D. Tapp and T. F. Thomas, J. Phys. Chem., 99, 14733 (1995). 


\section{Figure Captions:}

Figure 1. SEM of air and nitrogen annealed titania nanotubes at different annealing time points.

Figure 2. XRD patterns of a) as-grown anodised nanotubes b) anodised nanotubes annealed in air for $3 \mathrm{~h}$ and nanotubes annealed in nitrogen atmosphere for c) $1 \mathrm{~h} \mathrm{~d}$ ) $3 \mathrm{~h} \mathrm{e)} 5 \mathrm{~h}$.

Figure 3. N1s region X-ray photoelectron spectra of (a) air annealed and (b) $1 \mathrm{~h}$ nitrogen annealed titania nanotube samples.

Figure 4. O1s region scan of anodised sample annealed in nitrogen environment for $5 \mathrm{~h}$.

Figure 5. Linear sweep voltammogram of samples annealed in air and nitrogen at different time points under solar simulated light. The potential was swept from -1.0 to $+1.5 \mathrm{~V}$ vs SCE at a sweep rate $10 \mathrm{mV} / \mathrm{s}$.

Figure 6. Linear sweep voltammogram of sample annealed in nitrogen for $1 \mathrm{~h}$ under solar and visible illumination. The potential was swept from -1.0 to $+1.5 \mathrm{~V}$ vs SCE at the sweep rate $10 \mathrm{mV} / \mathrm{s}$.

Figure 7. Linear sweep voltammogram of annealed titania nanotube electrodes under solar simulated light in the presence of $0.1 \mathrm{M} \mathrm{NaClO}_{4}$ electrolyte containing $6.0 \mathrm{M} \mathrm{MeOH}$. The potential was swept from -1.0 to $+1.5 \mathrm{~V}$ vs $\mathrm{SCE}$ at a sweep rate $10 \mathrm{mV} / \mathrm{s}$.

Figure 8. Linear sweep voltammogram of samples annealed in air and nitrogen under solar simulated light in $\mathrm{NaClO}_{4}$ electrolyte and $\mathrm{NaClO}_{4}$ containing methanol. The potential was swept from -1.0 to +1.5 $\mathrm{V}$ vs SCE and the sweep rate was $10 \mathrm{mV} / \mathrm{s}$.

Figure 9. Linear sweep voltammogram of sample annealed in nitrogen for $1 \mathrm{~h}$ under visible illumination in $\mathrm{NaClO}_{4}$ electrolyte and $\mathrm{NaClO}_{4}$ containing methanol. The potential was swept from -1.0 to $+1.5 \mathrm{~V}$ vs SCE and the sweep rate was $10 \mathrm{mV} / \mathrm{s}$.

Figure 10. Photocurrent responses for titania nanotube electrodes annealed in air and nitrogen for 1, 3 , and $5 \mathrm{~h}$ at a fixed potential of $+1.0 \mathrm{~V}$ vs SCE measured under chopped solar illumination.

Figure 11. The current-time responses for air annealed electrode under chopped solar illumination in the range of applied potentials from $-0.8 \mathrm{~V}$ to $+1.0 \mathrm{~V}$ vs SCE.

Figure 12. The current-time responses for sample annealed in nitrogen for $1 \mathrm{~h}$ under chopped solar illumination in the range of applied potentials from $-0.8 \mathrm{~V}$ to $+1.0 \mathrm{~V}$ vs SCE. 
Figure 13. Current-time responses of electrodes annealed in air and nitrogen $(1 \mathrm{~h})$, under solar illumination in $\mathrm{NaClO}_{4}$ electrolyte only and $\mathrm{NaClO}_{4}$ containing $6.0 \mathrm{M}$ methanol measured at a fixed potential of $+1.0 \mathrm{~V}$ vs SCE.

Figure 14. Current time behaviour of air annealed electrode at fixed applied potentials ranging from -0.8 $\mathrm{V}$ to $+1.0 \mathrm{~V}$ vs SCE in the electrolyte containing $6.0 \mathrm{M} \mathrm{MeOH}$ under chopped solar illumination.

Figure 15. Current time behaviour of electrode annealed in nitrogen $(1 \mathrm{~h})$ at fixed applied potentials ranging from $-0.8 \mathrm{~V}$ to $+1.0 \mathrm{~V}$ vs $\mathrm{SCE}$ in the electrolyte containing 6.0 $\mathrm{M} \mathrm{MeOH}$ under chopped solar illumination.

Figure 16. Transient ratios plotted as a function of applied potentials from $-0.8 \mathrm{~V}$ to $+1.0 \mathrm{~V}$ vs SCE for electrodes annealed in air and nitrogen obtained from current-time responses measured under chopped solar illumination. 
List of figures:
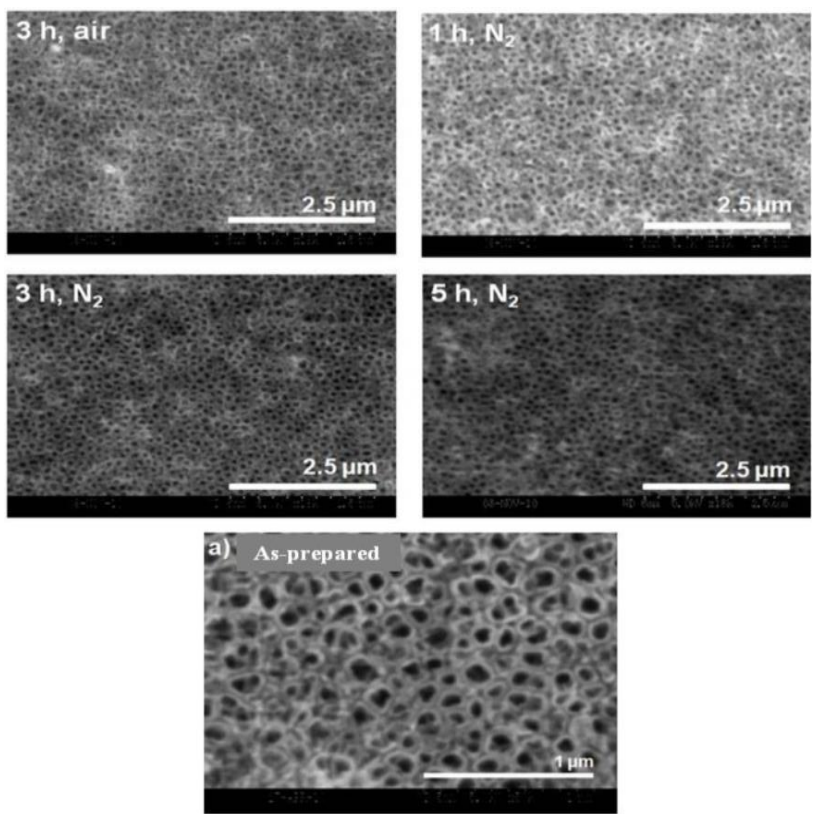

Figure 1

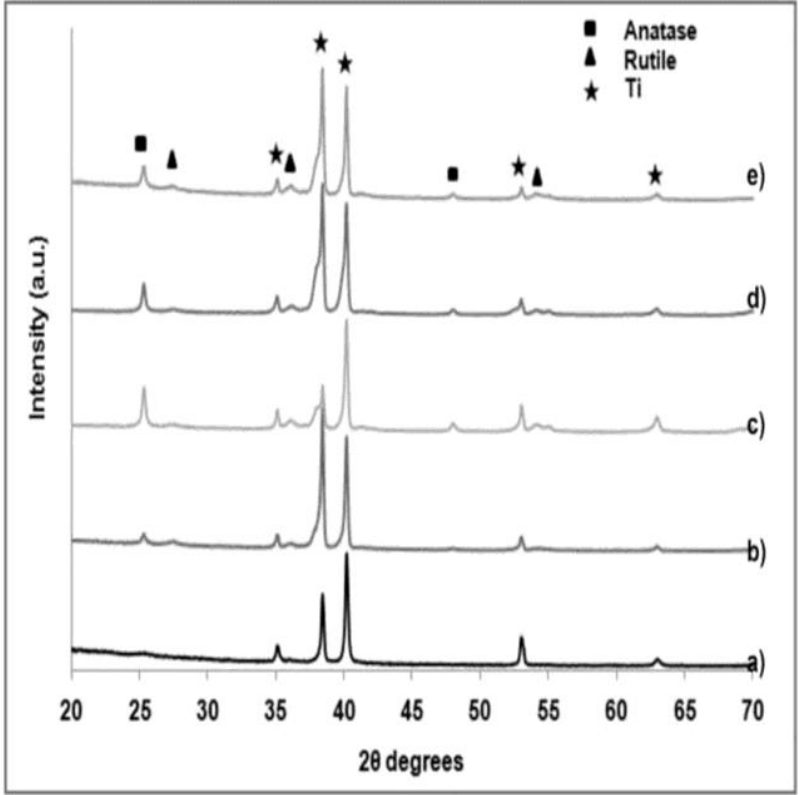

Figure 2 

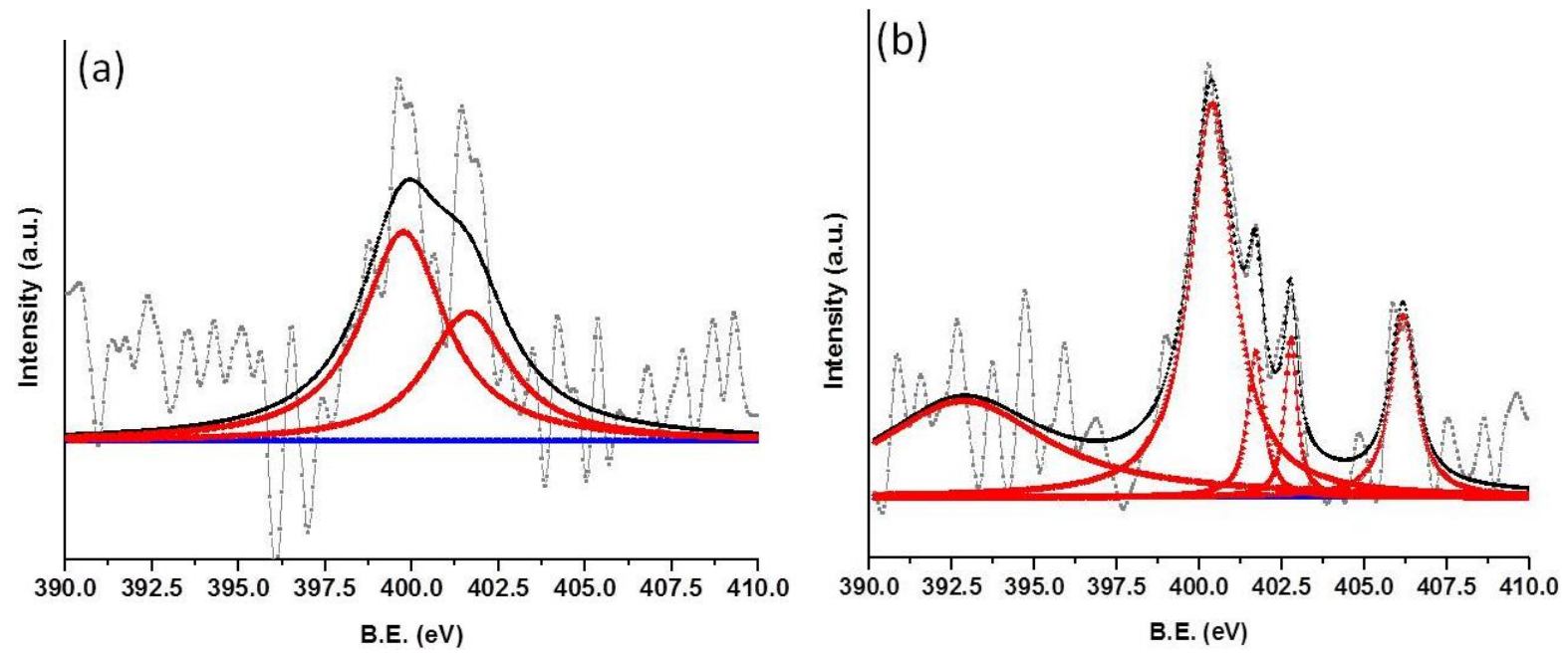

Figure 3

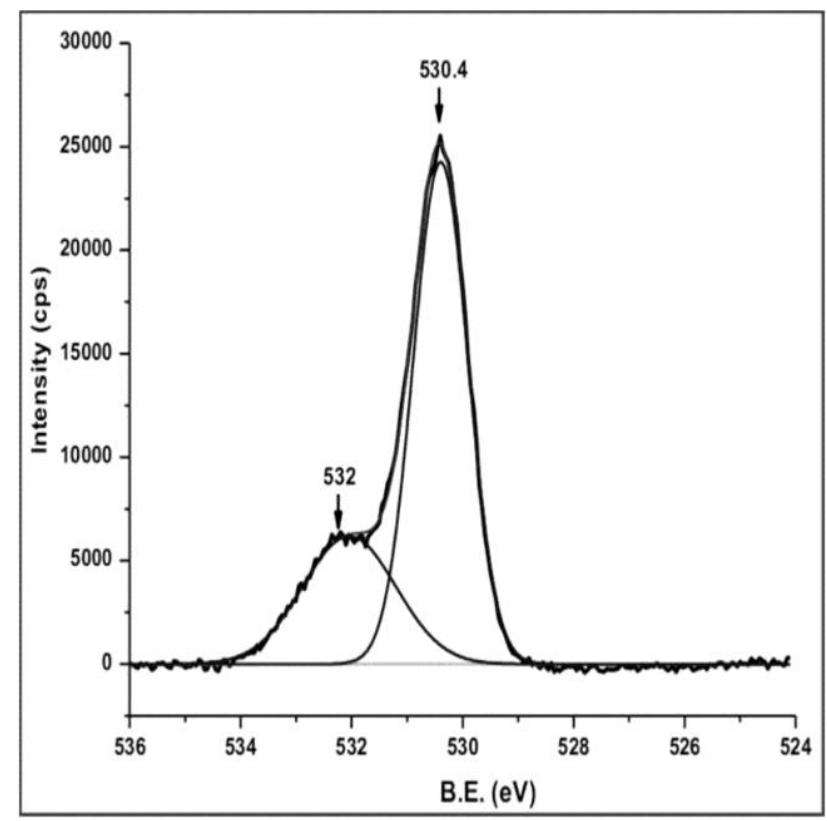

Figure 4 


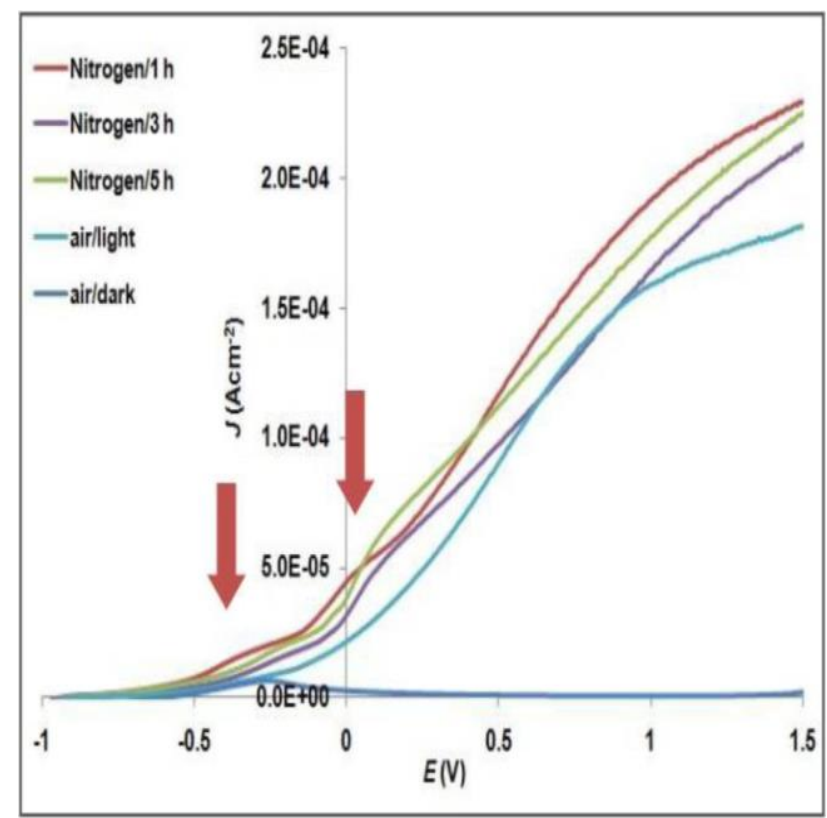

Figure 5

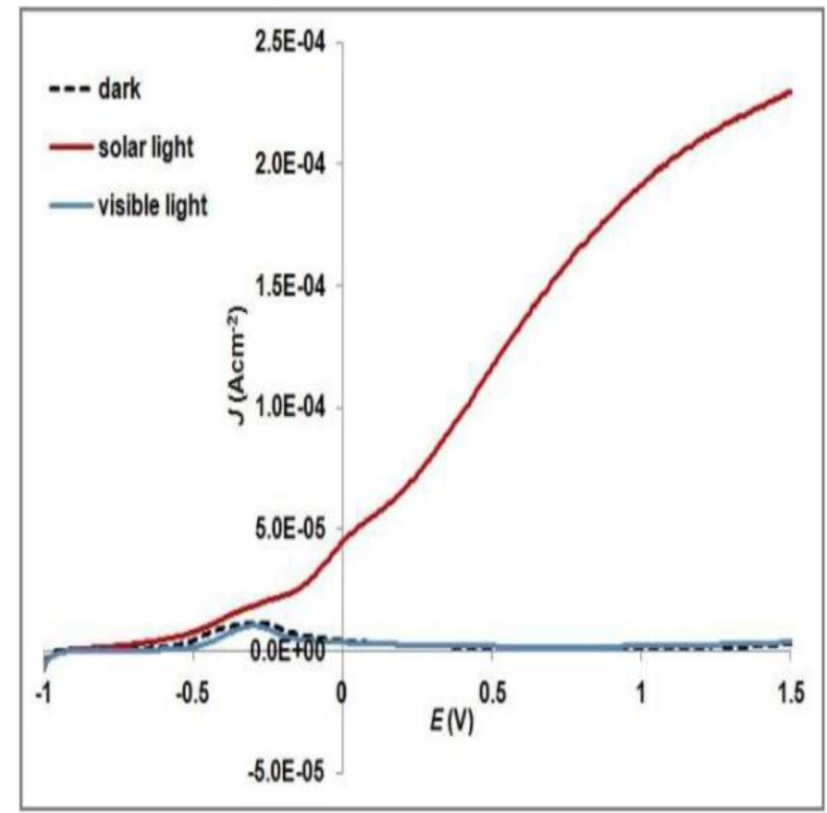

Figure 6 


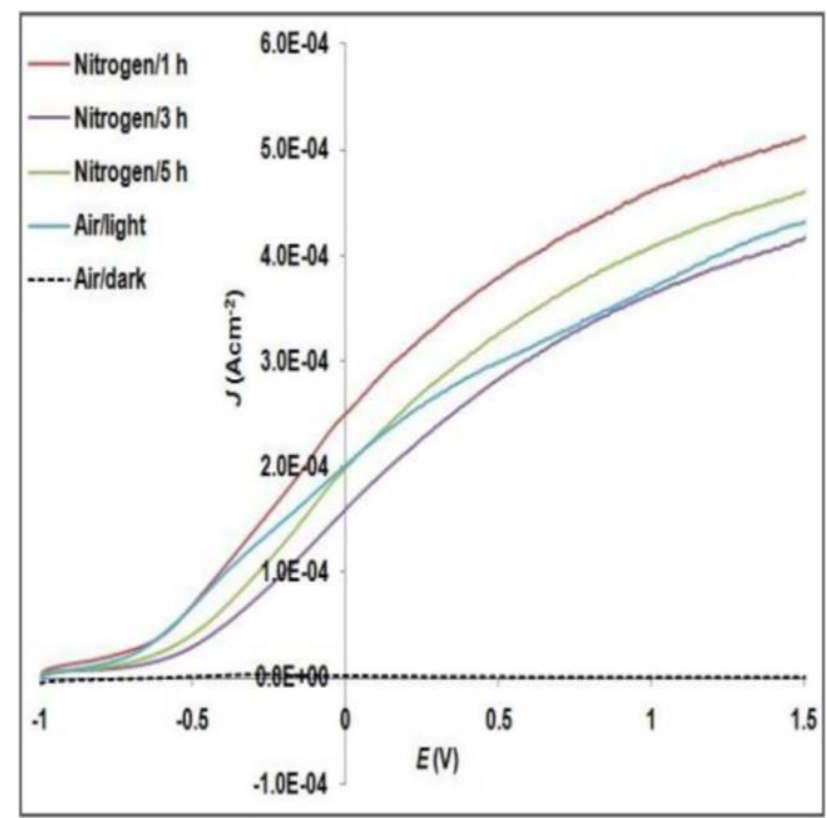

Figure 7

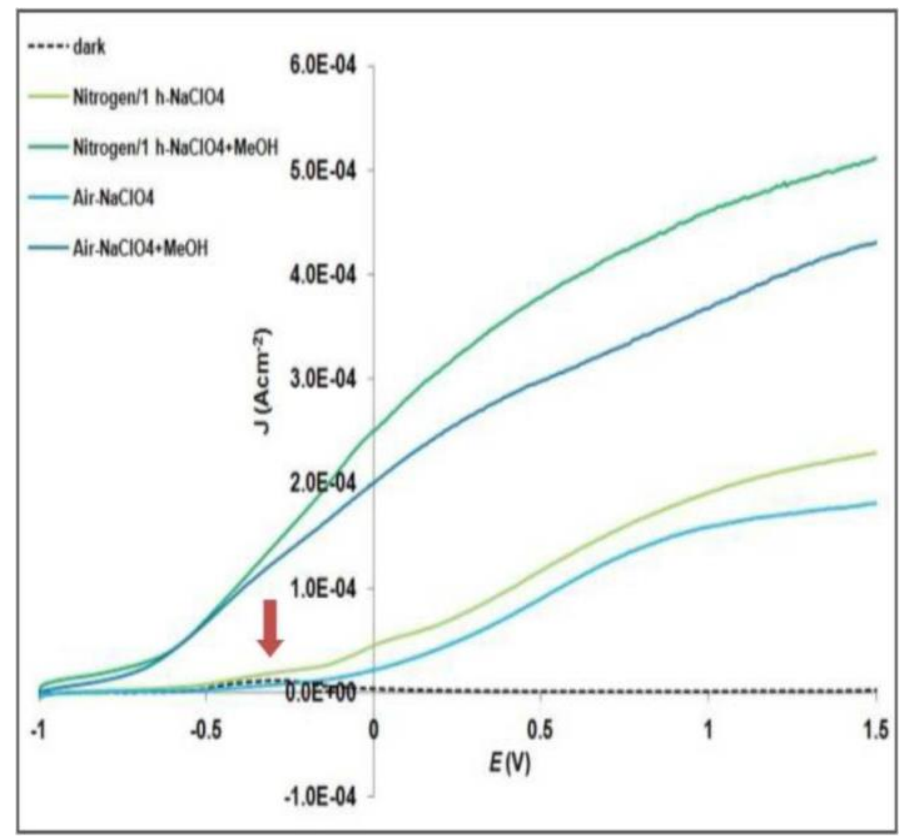

Figure 8 


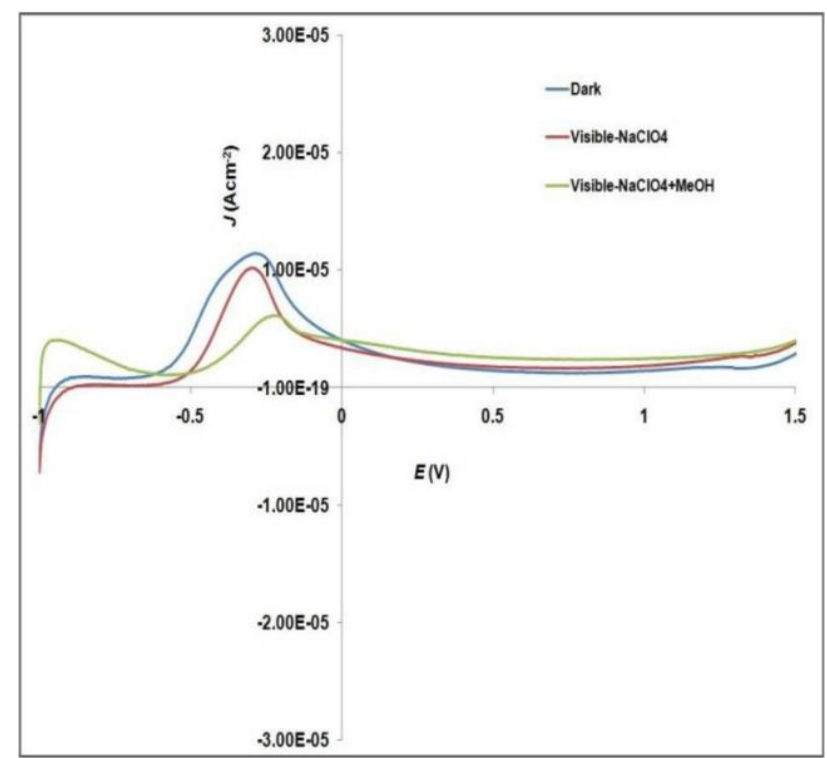

Figure 9

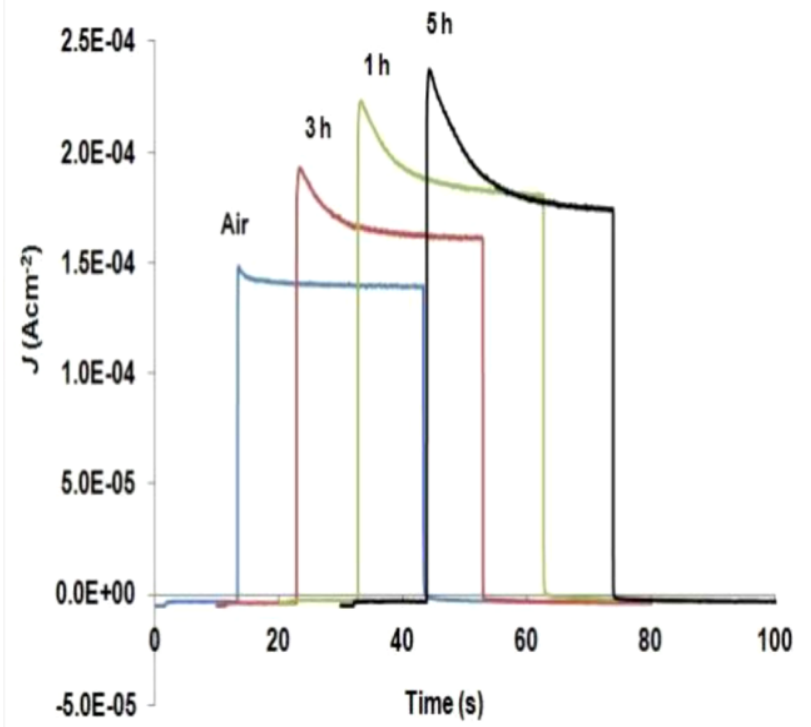

Figure 10 


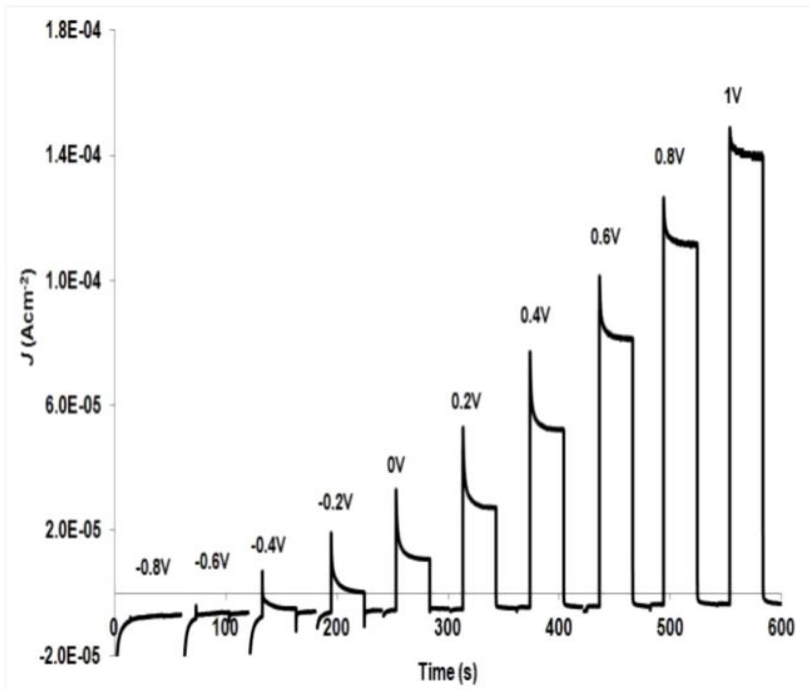

\section{Figure 11}

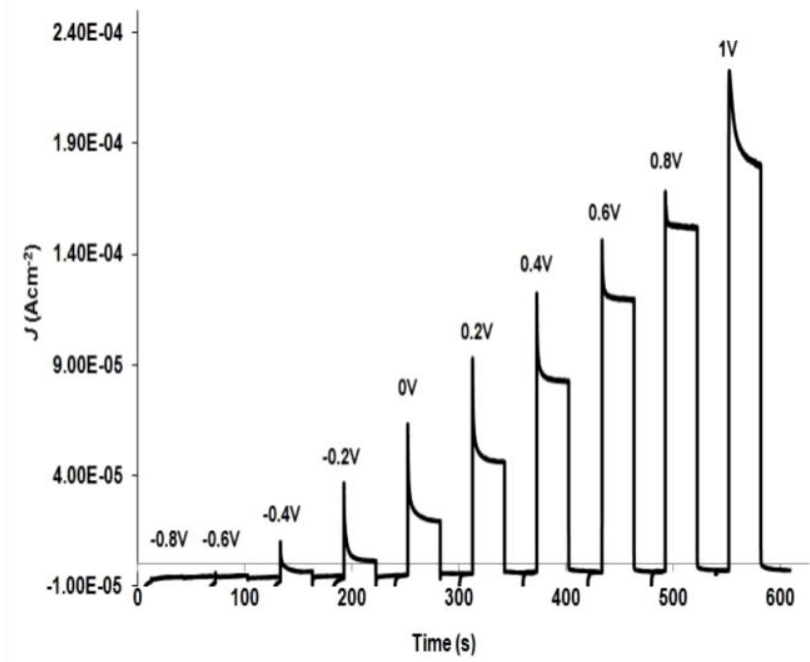

Figure 12 


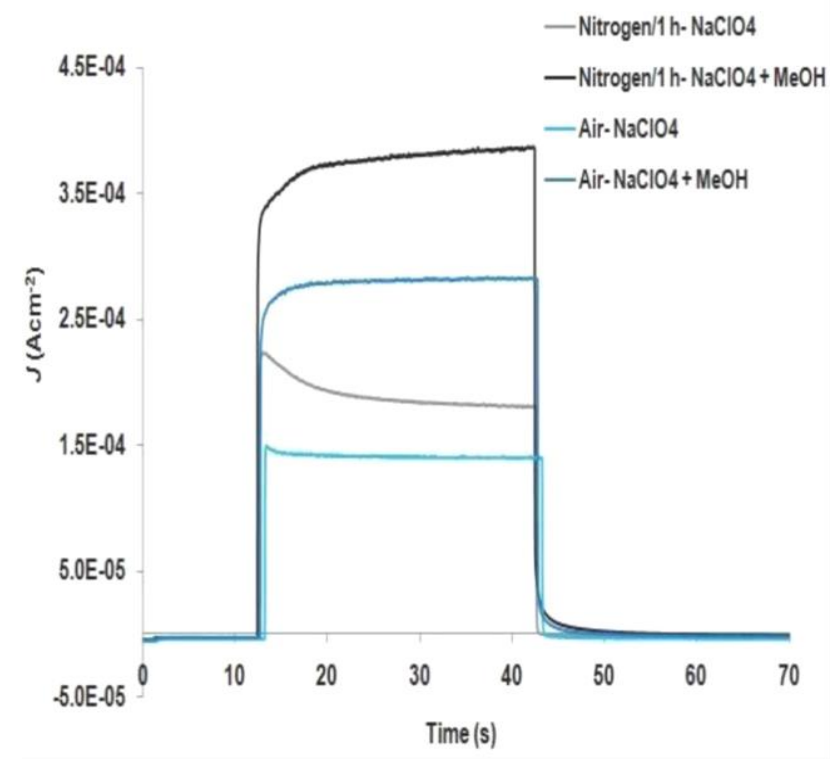

Figure 13

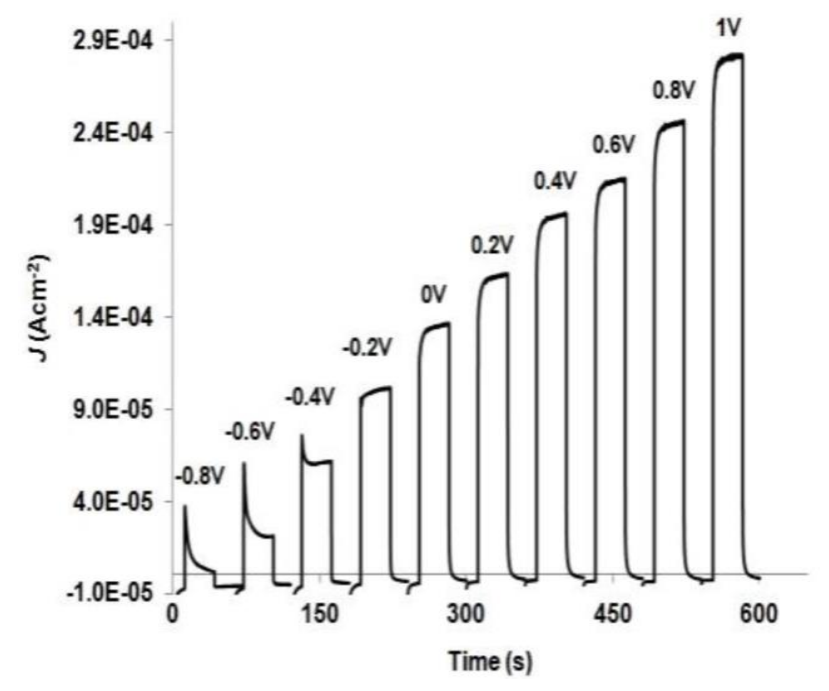

Figure 14 


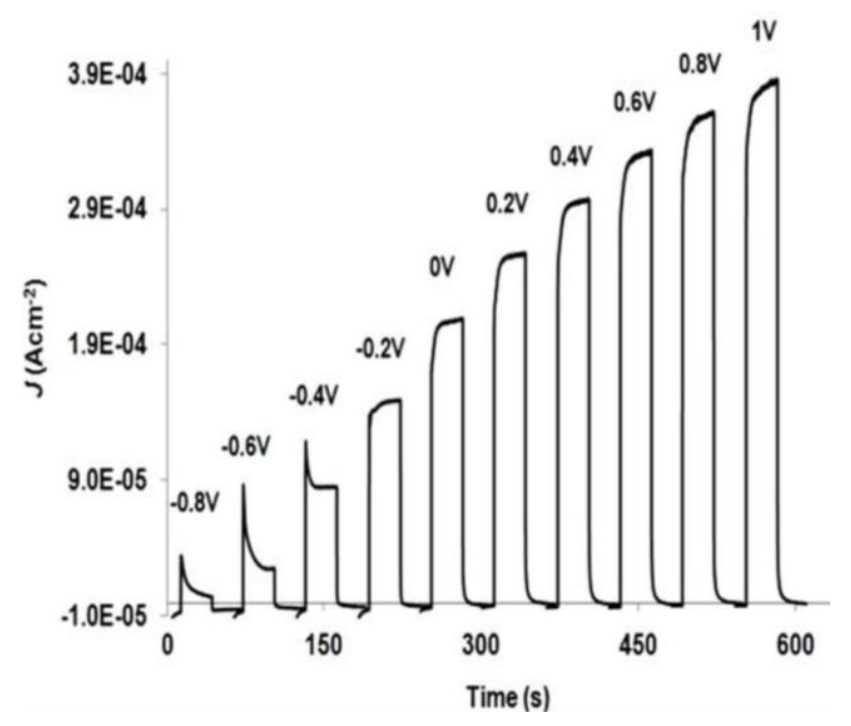

Figure 15

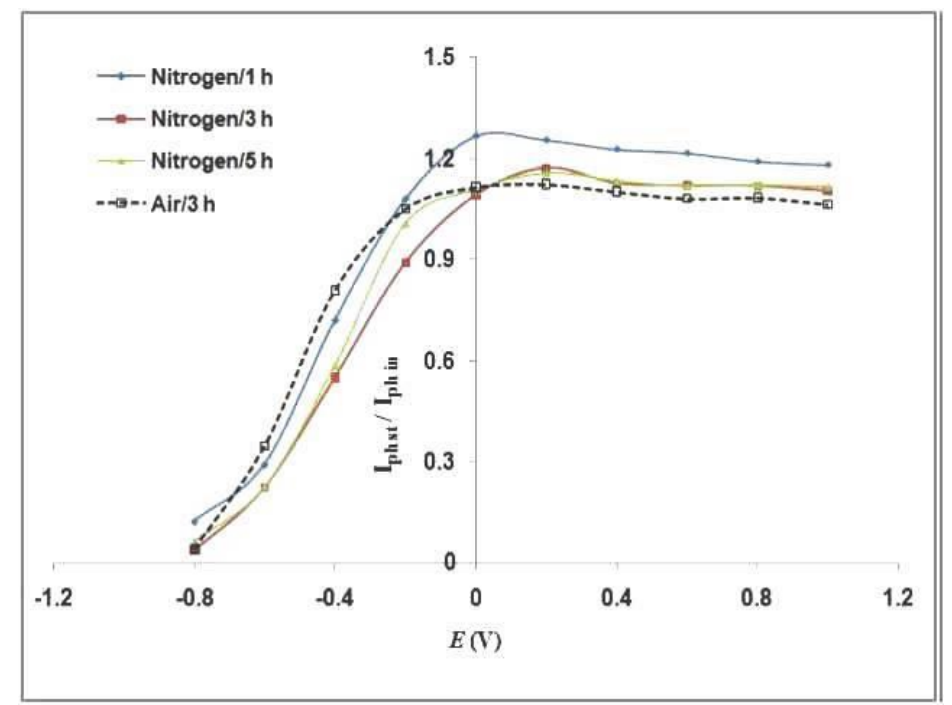

Figure 16 


\section{Tables}

Table 1 N1s binding energies estimated from XPS data for samples annealed in nitrogen environment.

\begin{tabular}{|lccc|}
\hline Samples & & B.E. $(\mathbf{e V})$ & \\
TiNT/air & - & - & - \\
TiNT/N $/ 1$ h & 402.6 & 400.1 & 398.5 \\
TiNT/N $/ 2$ h & 402.1 & 400.5 & 398.9 \\
TiNT/N $/ 2$ h & - & 400.3 & 398.9 \\
\hline
\end{tabular}

Table 2 XPS binding energy data for N1s region gathered from literature.

\begin{tabular}{|llll|}
\hline S.No. & Binding Energies $(\mathbf{e V})$ & Peak assignments & References \\
1. & $400.0,402.0$ & $\gamma-\mathrm{N}_{2}$ & $1,8,15$ \\
& 396.0 & $\beta-\mathrm{N}$ state in $\mathrm{TiO}_{2-\mathrm{x}} \mathrm{N}_{\mathrm{x}}$ structure & $1,8,15$ \\
2. & 400.1 & $\mathrm{O}-\mathrm{Ti}-\mathrm{N}$ structure & 16 \\
3. & $395.7,397.7,398.1,399.8,399.9$ & $\begin{array}{l}\text { Substitutional }(\mathrm{N})_{\mathrm{o}}, \text { interstitial }(\mathrm{N})_{\mathrm{i}}, \\
(\mathrm{NO})_{\mathrm{o}},\left(\mathrm{NO}_{2}\right)_{\mathrm{o}} \text { and }(\mathrm{NO})_{\mathrm{i}} \text { doping }\end{array}$ & 11 \\
4. & $399.7,407.4,409.7,415.7$ & $\mathrm{~N}_{2} \mathrm{O}_{2}^{2-}, \mathrm{NO}_{3}^{-}, \mathrm{NO}_{2}^{-}$species & 17 \\
5. & $398.5-398.9$ & $\mathrm{O}-\mathrm{Ti}-\mathrm{N}^{-}$structure & 18 \\
\hline
\end{tabular}

Table 3 Flat band potentials and critical band bending estimated for titania nanotube electrodes from individual responses measured under chopped solar illumination.

\begin{tabular}{|ccccc|}
\hline S.No. & Samples & $\boldsymbol{E}_{\mathbf{f b}}(\mathbf{V})$ & $\boldsymbol{E}(\mathbf{V})$ & $\left(\boldsymbol{E}-\boldsymbol{E}_{\mathbf{f b}}\right)(\mathbf{V})$ \\
1. & Air/3 h & -0.52 & +1.0 & 1.52 \\
2. & Nitrogen/1 h & -0.52 & +0.8 & 1.32 \\
3. & Nitrogen/3 h & -0.48 & +0.8 & 1.28 \\
4. & Nitrogen/5 h & -0.50 & +0.8 & 1.30 \\
\hline
\end{tabular}

